\title{
Bacteria-mediated bisphenol A degradation
}

\author{
Weiwei Zhang $\cdot$ Kun Yin $\cdot$ Lingxin Chen
}

Received: 27 February 2013 /Revised: 22 April 2013 / Accepted: 23 April 2013 / Published online: 17 May 2013

(C) Springer-Verlag Berlin Heidelberg 2013

\begin{abstract}
Bisphenol A (BPA) is an important monomer in the manufacture of polycarbonate plastics, food cans, and other daily used chemicals. Daily and worldwide usage of BPA and BPA-contained products led to its ubiquitous distribution in water, sediment/soil, and atmosphere. Moreover, BPA has been identified as an environmental endocrine disruptor for its estrogenic and genotoxic activity. Thus, BPA contamination in the environment is an increasingly worldwide concern, and methods to efficiently remove BPA from the environment are urgently recommended. Although many factors affect the fate of BPA in the environment, BPA degradation is mainly depended on the metabolism of bacteria. Many BPA-degrading bacteria have been identified from water, sediment/soil, and wastewater treatment plants. Metabolic pathways of BPA degradation in specific bacterial strains were proposed, based on the metabolic intermediates detected during the degradation process. In this review, the BPA-degrading bacteria were summarized, and the (proposed) BPA degradation pathway mediated by bacteria were referred.
\end{abstract}

Keywords Bisphenol A · Bacteria - Degradation ·

Degradation pathway

\section{Introduction}

Bisphenol A [2,2-bis(4-hydroxyphenyl)propane, BPA, CAS \# 80-05-7; made by combining acetone and phenol] is an organic compound with two phenol functional groups

W. Zhang $\cdot$ K. Yin $\cdot$ L. Chen $(\bowtie)$

Key Laboratory of Coastal Zone Environmental Processes and Ecological Remediation, Yantai Institute of Coastal Zone Research(YIC), Chinese Academy of Sciences (CAS),

Shandong Provincial Key Laboratory of Coastal Zone Environmental Processes, YICCAS, 17 Chunhui Road,

Yantai, Shandong 264003, People's Republic of China

e-mail: 1xchen@yic.ac.cn

K. Yin

University of Chinese Academy of Sciences, Beijing 100049,

People's Republic of China connected by a bridge attaching two methyl functional groups. BPA is widely used as a monomer in the synthesis of polycarbonate plastics, epoxy resins, flame retardants, food-drink packaging coating, and other specialty chemicals (Staples et al. 1998). The production of BPA is among the highest-production-volume chemicals, with a quantity of three million tons each year all over the world. Meanwhile, the worldwide demand and annual consumption of BPA is also increasing. BPA enters the environment mainly from the permitted discharges of industrial wastewater treatment plants (WWTPs), leachates of waste plastic in landfills, processing of BPA in manufacture, combustion of computer printed circuit boards in electronic waste, and spraying of paint (Peltonen and Pukkila 1988; Staples et al. 1998; Furhacker et al. 2000; Yamamoto et al. 2001; Cousins et al. 2002; Owens Jr. et al. 2007; Fu and Kawamura 2010; Huang et al. 2012). BPA discharged into water system counted for about $92 \%$ of its total emissions (European Commission 2003). Levels of BPA in different environments, including leachates from hazardous waste disposal sites, industrial wastewaters, influents and effluents of WWTPs, river water, seawater, sediment, and atmosphere were extensively assessed previously. The highest levels of BPA in the aquatic environment were detected in China mainland and Taiwan whereas the atmospheric levels of BPA in Indian megacities were roughly one order of magnitude higher than those in China, New Zealand, Japan, and the United States (Fu and Kawamura 2010; Huang et al. 2012).

The worldwide distribution of BPA in various environments was considered as the sources of BPA exposure to human beings (Kang et al. 2006b; Ulutao et al. 2011). Another way of exposure to BPA occurred through ingestion followed by accumulation in the fatty tissues (Oehlmann et al. 2008; Sanchez-Avila et al. 2009). In addition, BPA possesses estrogenic and genotoxic effects on both human beings and other organisms. BPA could interact with the estrogen receptor and affect the reproductive behavior (Staples et al. 1998; Snyder et al. 2001; Bonefeld-Jørgensen et al. 2007; Matsushima et al. 2007). BPA concentrations within 
the range of $0.1-10 \mu \mathrm{M}$ showed the estrogenic and mutagenic effects on human beings (Takahashi et al. 2001; Saiyood et al. 2010), while BPA concentrations within the range of 0.04 $0.4 \mu \mathrm{M}$ showed acute toxicity towards algae, invertebrates, and fish (Alexander et al. 1988). Therefore, BPA has been identified as one of the endocrine disrupting chemicals (EDCs) by the US Environmental Protection Agency, World Wide Fund For Nature. Due to its retention and harmful effects, the fate of BPA in the environments has become a social issue concerned by the public (Li et al. 2007). Thus, development of effective techniques to remove BPA from various environments are urgently recommended (Suzuki et al. 2004; Ying et al. 2008; Liu et al. 2011).

Methods to remove environmental pollutants, especially BPA, included photodegradation (Neamtu and Frimmel 2006), oxidation (Deborde et al. 2008), photoelectrocatalytic oxidation (Brugnera et al. 2010), and biodegradation (Kang et al. 2006a). Among all these methods, biodegradation has been proved to be an advanced technique to remove various pollutants from the environment. In our lab, efforts were made to investigate the biotransformation of heavy metals, and biodegradation of sulfonamide drugs, nitrofurans drugs, and EDCs by bacterial strains and their potential application in bioremediation (Zhang et al. 2012a, 2012b, 2012c, 2013). Bacterial community is readily catabolized to BPA, and BPA-degrading bacterial strains were isolated and identified from various environments (Kang et al. 2006a). BPA degradation by bacterial strains played a major role in the decomposition of BPA in the environment (Dorn et al. 1987; Staples et al. 1998), and biodegradation has also been proved to be an effective way to remove BPA from water, sediment, and soil. The information about BPA degradation by bacteria can, not only supply new techniques to remove BPA from the environment, but also improve our understanding of the fate of BPA in the environment. Detailed and general themes arising from BPA degradation by bacteria are described below.

\section{Bacteria-mediated BPA degradation}

BPA in the environment is mainly decomposed by a variety of microorganisms (Dorn et al. 1987; Staples et al. 1998). More and more BPA-degrading bacteria were isolated, identified, characterized, and used to treat BPA in WWTPs (Kang et al. 2006a; Melcer and Klecka 2011). BPAdegrading bacterial strains were isolated from soils, sludge, river, seawater, and even food sample (Table 1). These bacterial strains capable of growing on BPA as a sole source of carbon and energy included gram-negative strains Sphingomonas sp., Pseudomonas sp., Achromobacter sp., Novosphingobium sp., Nitrosomonas sp., Serratia sp., Bordetella sp., Alcaligenes sp., Pandoraea sp., Klebsiella sp., and Cupriavidus sp. and gram-positive strains Streptomyces sp., and Bacillus sp. Although there are many BPA- degrading bacteria in the environment, their BPA degradation ability are strongly different with strain specificity. Bacteria with high BPA biodegradability are limited. Many environmental factors such as biomass amount, temperature, $\mathrm{pH}$, metal ions, biological compounds, and oxygen affect their degradation efficiency. Based on the degrading metabolites of BPA generated by bacterial degradation, three dominant BPA degradation pathways in bacteria have already been proposed.

\section{BPA degradation by gram-negative bacteria}

Sphingomonas sp. strains were the most frequently isolated BPA-degrading bacteria, and all the isolated BPA-degrading Sphingomonas sp. strains could use BPA as the sole source of carbon and energy. The first BPA-degrading bacterial strain was isolated from the sludge of WWTP and was identified to be Sphingomonas sp. strain MV1 (Lobos et al. 1992; Spivack et al. 1994). Sphingomonas sp. strain MV1 could completely consumed $10 \mathrm{~g} / 1$ BPA within 4 days. Later, a Sphingomonas sp. strain TTNP3 was isolated from activated sludge sample obtained from laboratory-scale semi-continuous activated sludge unit, which was fed with nonylphenol for a period of approximately 4 months (Tanghe et al. 1999). However, its BPA degradation ability was firstly proposed by Kolvenbach et al. (2007). Sphingomonas sp. strain AO1 (or named Sphingomonas bisphenolicum strain AO1), with high BPA degradation efficiency, was isolated from the soil of a vegetablegrowing field in Japan (Sasaki et al. 2005b). It completely degraded $115 \mathrm{mg} / \mathrm{l} \mathrm{BPA}$ at the sixth hour and showed a little higher degradation efficiency than that of the three Sphingomonas sp. strains SO11, SO1a, and SO4a isolated by Matsumura et al. (2009) that completely degraded $115 \mathrm{mg} / \mathrm{l} \mathrm{BPA}$ within $15 \mathrm{~h}$. Sakai et al. (2007) reported the first seawater BPA-degrading isolate of Sphingomonas sp. strain BP-7. Its degradation efficiency could be enhanced by another non BPA-degrading bacterium Pseudomonas sp. strain BP-14. A mixture of Sphingomonas sp. strain BP-7 and Pseudomonas sp. strain BP-14 completely degraded $100 \mathrm{mg} / \mathrm{l} \mathrm{BPA}$ within 7 days, while Sphingomonas sp. BP7 alone needed about 40 days for complete consumption of BPA. Although Sphingomonas sp. strain BP-7 could use BPA as the sole source of carbon and energy, it could not degrade BPA on the mineral salt media. BPA degradation by Sphingomonas sp. strain BP-7 needed a nutrient supplement, such as peptone. Both Sphingomonas sp. strain BP-7 and Sphingomonas yanoikuyae strain BP-11R isolated by Yamanaka et al. (2008) efficiently degraded $300 \mathrm{mg} / \mathrm{l} \mathrm{BPA}$ in the presence of activated carbon (AC), suggesting that an efficient system for BPA removal can be constructed by introducing BPA-degrading bacteria into an AC treatment system. 
Table 1 Bacterial strains capable of degrading BPA

\begin{tabular}{|c|c|c|}
\hline Sources & Bacterial strains & References \\
\hline \multicolumn{3}{|c|}{ Sediment/soil } \\
\hline & Unidentified strain WH1 & Ronen and Abeliovich 2000 \\
\hline & Sphingomonas sp. strain AO1(or S. bisphenolicum strain AO1) & $\begin{array}{l}\text { Sasaki et al. 2005a and 2005b; Oshiman et } \\
\text { al. } 2007\end{array}$ \\
\hline & Pseudomonas sp. strain LBC1 & Telke et al. 2009 \\
\hline & Alcaligenes sp. strain OIT7 & Matsumura et al. 2009 \\
\hline & Bacillus sp. strains NO13, NO15 and YA27 & Matsumura et al. 2009 \\
\hline & Bordetella sp. strain OS17 & Matsumura et al. 2009 \\
\hline & Enterobacter sp. strains HI9 and HA18 & Matsumura et al. 2009 \\
\hline & Klebsiella sp. strains NE2, SU3 and SU5 & Matsumura et al. 2009 \\
\hline & Pandoraea sp. strain HYO6 & Matsumura et al. 2009 \\
\hline & $\begin{array}{l}\text { Pseudomonas sp. strains SU1, SU4, NAR11, FU12, NO14, KA16, SU19, FU20, } \\
\text { HUK21 and HUK22 }\end{array}$ & Matsumura et al. 2009 \\
\hline & Serratia sp. strain HI10 & Matsumura et al. 2009 \\
\hline & Sphingomonas sp. strains SO11,SO1a and SO4a & Matsumura et al. 2009 \\
\hline & Bacillus sp. strain GZB & Li et al. 2012 \\
\hline \multicolumn{3}{|l|}{ Water } \\
\hline & Pseudomonas sp. strain KA4 & Kang and Kondo 2002a and b \\
\hline & P. putida strain KA5 & Kang and Kondo 2002a and b \\
\hline & Streptomyces sp. & Kang et al. 2004 \\
\hline & Sphingomonas sp. strain BP-7 & Sakai et al. 2007; Yamanaka et al. 2008 \\
\hline & S. yanoikuyae strain BP-11R & Yamanaka et al. 2008 \\
\hline \multicolumn{3}{|c|}{ Bed reactor/sludge } \\
\hline & Sphingomonas sp. strain MV1 & Lobos et al. 1992; Spivack et al. 1994 \\
\hline & P. paucimobilis strain FJ-4 & $\begin{array}{l}\text { Ike et al. 1995; Ike et al. 2000; Ike et al. } \\
2002\end{array}$ \\
\hline & Sphingomonas sp. strain TTNP3 & Tanghe et al. 1999;Kolvenbach et al. 2007 \\
\hline & C. basilensis strain JF1 & Fischer et al. 2010 \\
\hline \multicolumn{3}{|c|}{ Leachate of waste } \\
\hline & A. xylosoxidans strain B-16 & Zhang et al. 2007 \\
\hline \multicolumn{3}{|c|}{ Rhizosphere of plant } \\
\hline & Novosphingobium sp. strain TYA-1 & Toyama et al. 2009 \\
\hline & Bacillus cereus strain BPW4 & Saiyood et al. 2010 \\
\hline & Enterobacter sp. strains BPR1 and BPW5 & Saiyood et al. 2010 \\
\hline \multicolumn{3}{|c|}{ Food of kimchi } \\
\hline & B. pumilus strains BP-2CK, BP-21DK and BP-22DK & Yamanaka et al. 2007 \\
\hline \multicolumn{3}{|c|}{ Unidentified place } \\
\hline & P. monteilii strain $\mathrm{N}-502$ & Masuda et al. 2007 \\
\hline & N. europaea & Roh et al. 2009 \\
\hline
\end{tabular}

BPA degradation pathways proposed in the above Sphingomonas sp. strains were described in Fig. 1. (1) The first BPA degradation pathway was described in Sphingomonas sp. strain MV1. BPA degradation by Sphingomonas sp. strain MV1 occurred via several rearrangements involving phenonium ion intermediates. Through the solvolysis of the first phenonium ion intermediate (compound IV), BPA was catabolized into two metabolites, 2,2-bis(4-hydroxyphenyl)-1-propanol (compound I, a minor metabolite) formed by the hydroxylation of methyl group, and 1,2-bis(4-hydroxyphenyl)-2-propanol (compound II, a major metabolite), formed by the hydroxylation of the quaternary carbon (Spivack et al. 1994). (2) Both compounds I and II were detected in Sphingomonas sp. strain AO1, but it was proposed that the formation of compound II was through another intermediate (compound V). Because the study of Sasaki et al. (2005a) was focused on the function of cytochrome P450 monooxygenase system in BPA degradation, further degradation of compounds I and II was not investigated. (3) BPA 


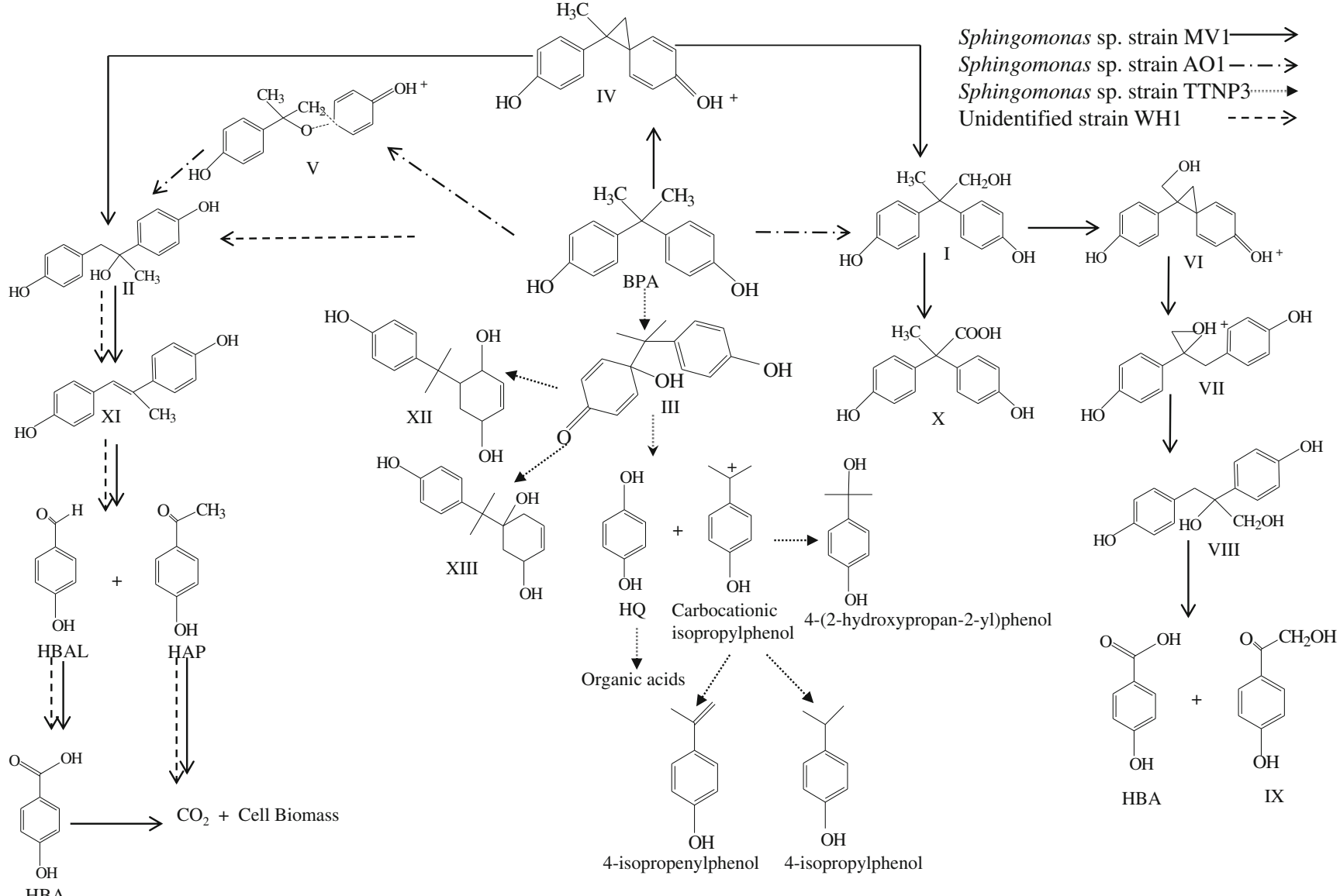

Fig. 1 The proposed BPA degradation pathways in Sphingomonas sp. strains MV1, AO1 and TTNP3 and the unidentified strain WH1

degradation via a type II ipso substitution mechanism occurred in Sphingomonas sp. strain TTNP3. Different from the BPA degradation through the formation of phenoniumion intermediates, the first step of BPA degradation in Sphingomonas sp. strain TTNP3 was to introduce one atom of molecular oxygen into the BPA by the NADPH and FAD-aided monooxygenase to form a quinol intermediate (compound III). Then, the breakage of $\mathrm{C}-\mathrm{C}$ bond between the phenolic moiety and the isopropyl group of BPA occurred (Kolvenbach et al. 2007).

Compound I was further metabolized in Sphingomonas sp. strain MV1 (Lobos et al. 1992; Spivack et al. 1994). Oxidation and rearrangement were simultaneously taking place in compound I to form another intermediate (compound VI), which has the $\mathrm{C} 1$ hydroxyl positioned for internal displacement to form the oxirane (compound VII). Subsequent hydrolysis of the oxirane mainly led to the production of the 2,3-bis (4-hydroxyphenyl)-1,2-propanediol (compound VIII). 2,3bis(4-Hydroxyphenyl)-1,2-propanediol was then degraded very slowly into 4-hydroxybenzoic acid (HBA) and 4hydroxyphenacyl alcohol (compound IX). A minor pathway to further oxidize compound I was the formation of 2,2-bis(4hydroxyphenyl)propanoic acid (compound X). Further oxidation of compound II was also proposed in Sphingomonas sp. strain MV1 (Lobos et al. 1992; Spivack et al. 1994). Compound II was dehydrated to 4,4'-dihydroxy- $\alpha$ methylstilbene (compound XI), and then the oxidative cleavage took place, leading to the formation of 4-hydroxybenzaldehyde (HBAL) and 4-hydroxyacetophenone (HAP). HBAL was then subsequently oxidized to HBA. Finally, both HAP and HBA were completely metabolized by Sphingomonas sp. strains MV1 without the production of any HPLC-UV detectable products. Compound III was mainly further metabolized by Sphingomonas sp. strain TTNP3 through the cleavage of the $\mathrm{C}-\mathrm{C}$ bond between the phenolic moiety and the isopropyl group of BPA to form p-hydroquinone (HQ) and a carbocationic isopropylphenol. HQ was further degraded into organic acids. The carbocationic isopropylphenol was metabolized in two pathways: One way was the formation of 4-(2hydroxypropan-2-yl)phenol through the reaction with water. Another way was the formation of 4-isopropenylphenol and 4-isopropylphenol by the way of the loss of $\mathrm{H}^{+}$and the addition of $\mathrm{H}^{-}$, respectively, as the side reactions. Metabolism of compound III was also occurred to form two other possible degrading metabolites 2-[2-(4-hydroxyphenyl)propan-2- 
yl]cyclohex-2-ene-1,4-diol (compound XII) or 1-[2-(4hydroxyphenyl)propan-2-yl]cyclohex-2-ene-1,4-diol (compound XIII), by a NIH shift with subsequent hydrogenations of the hydroxylated ring or direct successive hydrogenations of the ring of the quinol intermediate (Kolvenbach et al. 2007).

Pseudomonas sp. strain was another kind of BPAdegrading bacteria that were frequently isolated from the environment and grown on BPA as the sole carbon and energy source. Psudomonas paucimobilis strain FJ-4 was isolated from sludge taken from a WWTP at an epoxy resin-manufacturing facility by Ike et al. (1995). It could efficiently degrade $100 \mathrm{mg} / \mathrm{l}$ BPA to a concentration below the limit of detection within $12 \mathrm{~h}$. Later, a Pseudomonas sp. strain KA4 and a Pseudomonas putida strain KA5 were isolated by Kang and Kondo (2002a and b). Both of the Pseudomonas sp. strains degraded about $90 \%$ of BPA when the initial BPA concentration was $1 \mathrm{mg} / \mathrm{l}$. A Pseudomonas monteilii strain N-502 with high BPA degradation ability was isolated by Masuda et al. (2007). It completely degraded $500 \mathrm{mg} / \mathrm{l} \mathrm{BPA}$ within 10 days, and its degradation efficiency could be accelerated by 1 and $10 \mathrm{mM} \mathrm{Ca}{ }^{2+}, \mathrm{Mg}^{2+}$, and folic acid to different degrees. Matsumura et al. (2009) reported other ten Pseudomonas sp. strains SU1, SU4, NAR11, FU12, NO14, KA16, SU19, FU20, HUK21, and HUK22 that could completely degrade $115 \mathrm{mg} / \mathrm{l}$ BPA. Moreover, BPA degradation by Pseudomonas sp. strains SU1 and SU4 introduced some degrading metabolites that were different from the metabolites produced by Sphingomonas sp. strain AO1. Thus, it was postulated that Pseudomonas sp. strains SU1 and SU4 may exhibit novel BPA degradation pattern which was distinctly different from those of Sphingomonas sp. strain AO1 (Matsumura et al. 2009).

BPA degradation by Achromobacter xylosoxidans strain B16 and Cupriavidus basilensis strain JF1 was also reported (Zhang et al. 2007; Fischer et al. 2010). BPA-degrading $A$. xylosoxidans strain B-16 was isolated from the compost leachate of the municipal solid waste. It could grow using BPA as the sole carbon source and degrade $86.83 \%$ of $5 \mathrm{mg} / \mathrm{l} \mathrm{BPA}$ at the seventh day. Like other bacterial strains, the optimal temperature and $\mathrm{pH}$ for BPA degradation by $A$. xylosoxidans were found to be $35-37{ }^{\circ} \mathrm{C}$ and 7.0 , respectively. Higher temperature promoted BPA degradation within the range of temperature lower than $37^{\circ} \mathrm{C}$. Temperature higher than $37^{\circ} \mathrm{C}$ inhibited bacterial growth and subsequently affected the BPA biodegradation activity (Kang and Kondo 2002a, b; Zhang et al. 2007; Li et al. 2012). The optimal $\mathrm{pH}$ and temperature for BPA degradation may due to the greatest biomass and BPAdegrading enzymatic activity under the optimal conditions (Zhang et al. 2007). According to the metabolic intermediates HBAL, HBA and HQ, the BPA degradation by $A$. xylosoxidans strain B-16 was in the following pathways: BPA was firstly decomposed to form three intermediates HAP (not detected), HBAL and 4-isopropenylphenol (not detected). Subsequently, HBAL was converted to $\mathrm{CO}_{2}$ and biomass directly. HAP was oxidized to form HBA, followed by the conversion to $\mathrm{CO}_{2}$ and biomass. 4-Isopropenylphenol was converted to HQ by $\mathrm{OH}$ radicals attack, which was different from the way of HQ formation in Sphingomonas sp. strain TTNP3 via ipso-hydroxylation after the alkyl substituent left the quinol intermediate and mineralized later (Ohko et al. 2001; Kaneco et al. 2004; Zhang et al. 2007). However, detailed degradation pathway from BPA to HAP (a proposed metabolite), HBAL, and 4-isopropenylphenol (a proposed metabolites) was not further investigated by Zhang et al. (2007). C. basilensis strain JF1 isolated from a planted fixed-bed reactor continuously running with BPA was also able to use BPA as sole carbon and energy source; however, its BPA degradation efficiency was lower. $C$. basilensis strain JF1 could use phenol as a co-substrate during BPA degradation. It completely consumed $1.7 \mathrm{mM}$ phenol at the first $2 \mathrm{~h}$ and then degraded $90 \%$ of $38.8 \mathrm{mg} / 1 \mathrm{BPA}$ after 225 days. Based on the detected metabolites 4-isopropenylphenol, 4-(2-propanol)-phenol, HAP, HBAL, HBA, and HQ, BPA degradation pathway in C. basilensis strain JF1 was proposed by Fischer et al. (2010) in the light of previous BPA degradation pathways. C. basilensis strain JF1 seemed to mineralize BPA in a pathway different from the degradation pathway in Sphingomonas sp. strain MV1 proposed by Lobos et al. (1992) and Spivack et al. (1994) but in a pathway similar to that in Sphingomonas sp. strain TTNP3 proposed by Kolvenbach et al. (2007), with minor difference. 4-(2-Propanol)-phenol and HQ were the products of cleavage of the ring of BPA. HQ was then completely mineralized by $C$. basilensis strain JF1. 4-(2-Propanol)-phenol was further metabolized in the following two pathways: The main product 4-isopopenylphenol was formed by the elimination of $\mathrm{H}_{2} \mathrm{O}$ at the phenol residue and another product HAP was formed by the splitting of a C1-body. Both 4-isopropenylphenol and HAP were oxidized to HBAL and HBA via ortho-degradation pathway sequentially. Finally, HBA was mineralized by $C$. basilensis strain JF1 (Fig. 2) (Fischer et al. 2010).

Other novel species of BPA-degrading bacteria were also isolated. An unidentified bacterial strain WH1, closely resembling Sphingomonas sp., was isolated from sediment obtained from the vicinity of an industrial complex in the northern Negev in Israel. WH1 could use BPA as a sole source of carbon and energy and completely degrade $205 \mathrm{mg} / \mathrm{l} \mathrm{BPA}$ at the eighth day. BPA degradation by WH1 was proposed to be via the main degradation pathway occurred in Sphingomonas sp. strain MV1, based on the detectable metabolites of HBA and HAP (Ronen and Abeliovich 2000) (Fig. 1). Matsumura et al. (2009) reported that three Klebsiella sp. strains NE2, SU3, and SU5; two Enterobacter sp. strains HI9 and HA18; one Alcaligenes sp. strain OIT7; one Bordetella sp. strain OS17; one Pandoraea sp. strain HYO6; and one Serratia sp. strain HI10 could completely degrade $115 \mathrm{mg} / \mathrm{l} \mathrm{BPA}$, respectively. Three 


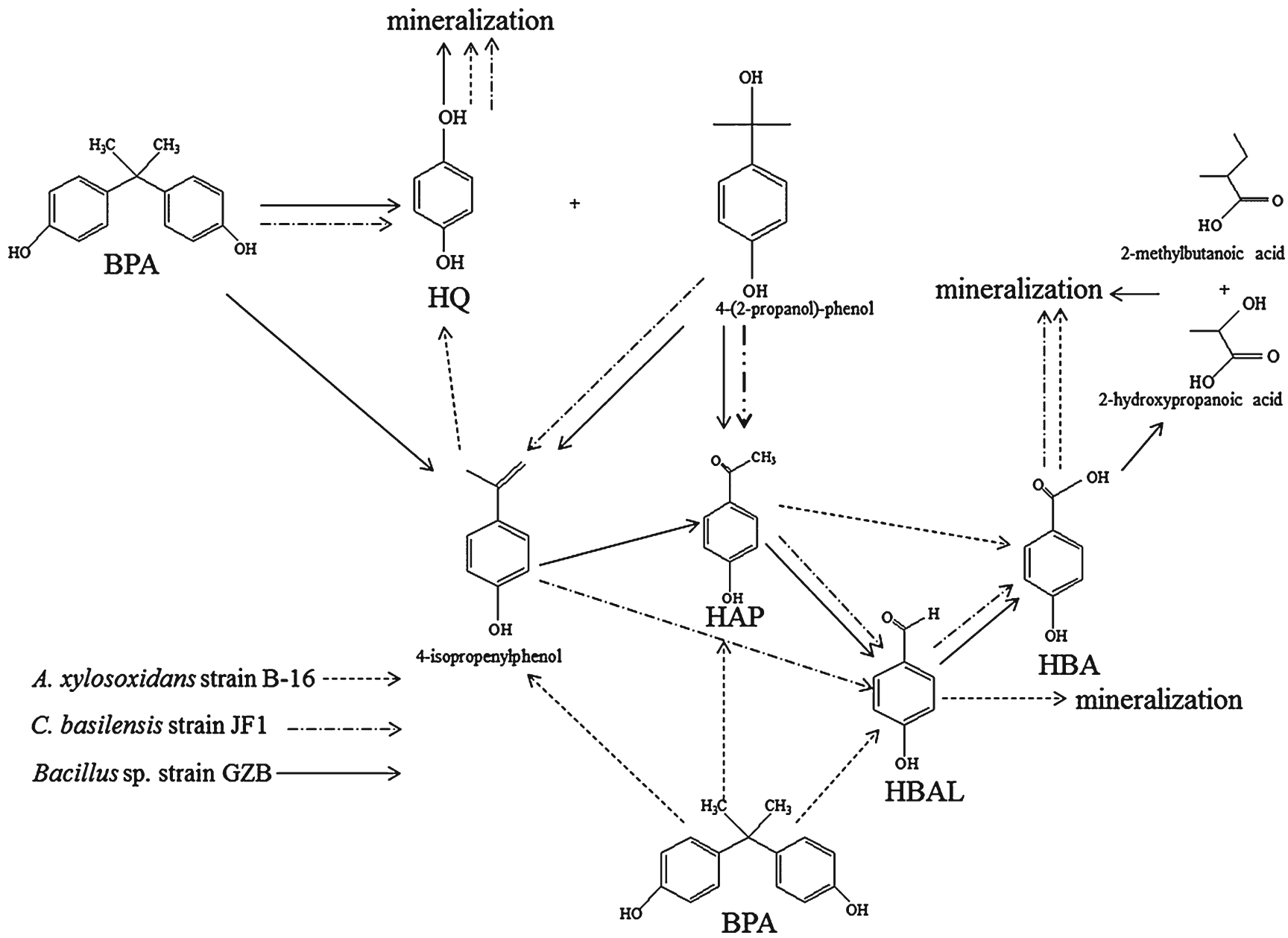

Fig. 2 The proposed BPA degradation pathways in A. xylosoxidans strain B-16, C. basilensis strain JF1 and Bacillus sp. strain GZB

gram-negative bacterial strains, Novosphingobium sp. strain TYA-1, and Enterobacter sp. strains BPR1 and BPW5, were isolated from the rhizosphere of plants with BPA removal capacity. Novosphingobium sp. strain TYA-1 was isolated from the rhizosphere of Phragmites australis. It could grow on BPA as the sole carbon source and completely degrade 22.8-228.3 mg/l BPA within $24 \mathrm{~h}$ (Toyama et al. 2009). Enterobacter sp. strains BPR1 and BPW5 were found to be associated with the plant Dracaena sanderiana and adhered at the root surface to play a significant role in BPA biodegradation. All the identified strains could enhance BPA dissipation in the plant hydroponic system (Saiyood et al. 2010).

Three enzymes had been reported to be involved in BPA degradation. The presence of metyrapone, an inhibitor of cytochrome P450, contributed to the reduction in the cell growth and BPA degradation efficiency of Sphingomonas sp. strain AO1. In the presence of $\mathrm{NADH}$, the purified components of P450 monooxygenase degraded BPA into 2,2-bis(4-hydroxyphenyl)-1-propanol and 1,2-bis(4hydroxyphenyl)-2-propanol via hydroxylation of the methyl group and the quaternary carbon, respectively. The $\mathrm{P} 450_{\text {bisd }}$ monooxygenase system was predicted to catalyze the hydroxylation of either a $\mathrm{C}$ atom of a methyl group (C-8 or C-9) or the quaternary carbon (C-7) attacked by $\mathrm{H}_{2} \mathrm{O}$ (Sasaki et al. 2005a, 2005b; Oshiman et al. 2007). P450 monooxygenase was also the initial enzyme that led to ipso substitution in other xenobiotics containing phenol with a quaternary-carbon (Kolvenbach et al. 2007). Ammonia monooxygenase (AMO) was another enzyme that was involved in BPA degradation. Degradation efficiency of a Nitrosomonas europaea strain was inhibited by the presence of allylthiourea, an inhibitor of AMO (Roh et al. 2009). The decreased removal efficiency of nitrifierenriched activated sludge in the presence of allylthiourea or $\mathrm{Hg}_{2} \mathrm{SO}_{4}$ was also observed by Kim et al. (2007). An extracellular laccase from a Pseudomonas sp. strain LBC1 completely degraded $36.5 \mathrm{mg} / \mathrm{l} \mathrm{BPA}$ within $5 \mathrm{~h}$. Compared with eukaryotic laccases and peroxidases, this extracellular laccase is a more efficient biocatalyst for the complete removal of BPA without the requirement of other redox mediators (Telke et al. 2009). 
BPA degradation by gram-positive bacteria

The first gram-positive BPA-degrading bacterium was a Streptomyces sp. strain isolated from river water by Kang et al. (2004). The Streptomyces sp. strain degraded $90 \%$ of $1 \mathrm{mg} / \mathrm{l} \mathrm{BPA}$ in the river water at the fourth day and then showed little degradation activity. The most prevalent grampositive BPA-degrading bacteria were Bacillus sp. Three Bacillus pumilus strains BP-2CK, BP-21DK, and BP22DK were isolated from kimchi, a traditionally fermented food, by Yamanaka et al. (2007). The three B. pumilus strains efficiently degraded $10 \mathrm{mg} / \mathrm{l}$ BPA within 20-40 h, in media supplemented with nutrients. The $12.5 \% \mathrm{NaCl}$ and $100 \mathrm{mg} / 1 \mathrm{BPA}$ showed complete inhibitory effects on both cell growth and degradation activity. B. pumilus strains BP2CK, BP-21DK, and BP-22DK were unable to grow using BPA as the sole carbon source. Similarly, other two Bacillus sp. strains NO13 and NO15 isolated from soil samples by Matsumura et al. (2009) were also unable to grow and degrade BPA in mineral salt media with BPA as the sole carbon source whereas both strains completely degraded $115 \mathrm{mg} / \mathrm{l} \mathrm{BPA}$ in media supplied with tryptone and yeast extract. This phenomenon was consisted with the fact that many strains belonging to Bacillus sp. require growth factors, and B. pumilus strains require biotin and amino acids according to Bergey's Manual of Systematic Bacteriology (Sneath et al. 1986). Thus, addition of nutrients was effective for the growth and BPA degradation ability of the three Bacillus sp. strains. This should also interpret why the genus Bacillus sp. capable of degrading BPA had not been isolated with the conventional enrichment techniques using mineral salt media containing BPA as the sole carbon source (Yamanaka et al. 2007). A Bacillus sp. strain YA27 isolated from soil samples by Matsumura et al. (2009) and Bacillus sp. strain GZB isolated by Li et al. (2012) were able to grow using BPA as the sole carbon source. Bacillus sp. strain YA27 degraded $50 \mathrm{mg} / 1 \mathrm{BPA}$ in media supplied with tryptone and yeast extract. Bacillus sp. strain GZB was isolated from sediment of a creek in an electronic-waste recycling site and removed $100 \%$ of $5 \mathrm{mg} / \mathrm{l}$ BPA under optimal aerobic conditions ( $\mathrm{Li}$ et al. 2012). Similar to the synergistic effect of the biomass amount and BPA degradation observed by Zhang et al. (2007), more bacterial cells could increase not only the degradation efficiency but also the degradation rate of Bacillus sp. strain GZB. However, no such positive relationship between the biomass amount and BPA degradation was observed in seawater. The difference may be due to the size of bacterial cell counts that can perform the fast and complete BPA degradation, or due to the existence of other chemical degradation of BPA, such as degradation by reactive oxygen species, in seawater (Klecka et al. 2001; Sajiki and Yonokubo 2002, 2003; Kang and Kondo 2005; Zhang et al. 2007). The substrate concentration was another factor that affected BPA degradation. The degradation efficiency of Bacillus sp. GZB decreased from 92.9 to $66.3 \%$ as BPA concentration rose from 5 to $30 \mathrm{mg} / 1$. Under anaerobic condition, Bacillus sp. strain GZB could use $\mathrm{Fe}^{3+}$ as an alternative electron acceptor to degrade BPA, although its degradation efficiency was slightly lower than that of using $\mathrm{O}_{2}$. Under both anaerobic and aerobic conditions, $10 \mathrm{mg} / 1$ BPA was completely degraded by Bacillus sp. strain GZB within 100 h. Thus, Bacillus sp. GZB provided a promising alternative for treatment of BPA contamination when bioremediation had to be taken under anaerobic condition ( $\mathrm{Li}$ et al. 2012).

BPA degradation pathway in Bacillus sp. strain GZB under aerobic conditions was similar to that proposed in $C$. basilensis strain JF1 with minor difference (Li et al. 2012). 4-(2-Propanol)-phenol and HQ were also identified as the first two metabolites. HQ could be completely mineralized by Bacillus sp. strain GZB. 4-(2-Propanol)-phenol was oxidized to HAP and then demethylated to form HBAL followed by the conversion to HBA through the same pathway described in C. basilensis strain JF1. Another metabolite 4-isopropenylphenol was formed from direct cleavage of BPA and also from the dehydration of 4-(2-propanol)phenol, which was also frequently found in photocatalytic degradation of BPA pathway (Nomiyama et al. 2007). 4Isopropenylphenol was then further oxidized to HAP, HBAL, and HBA subsequently. Two small molecular products 2-hydroxypropanoic acid and 2-methylbutanoic acid were derived from the breakage of benzene ring and were completely mineralized to $\mathrm{CO}_{2}$ and $\mathrm{H}_{2} \mathrm{O}$ (Fig. 2). However, different BPA degradation pathways may exist in other gram-positive BPA-degrading bacterial strains. HAP produced by other BPA-degrading bacterial strains was not detected in the metabolites of BPA generated by B. pumilus strains BP-2CK, BP-21DK, and BP-22DK (Yamanaka et al. 2007). Metyrapone could not inhibit BPA degradation ability of Bacillus sp. strain YA27 (Matsumura et al. 2009), which also indicated that Bacillus sp. strain YA27 might possess a unique BPA degradation pathway.

Challenge in the study of BPA degradation by bacterial strains

Degrading metabolites of BPA under aerobic conditions were exhaustively studied, and several BPA degradation pathways were proposed. However, only a few reports focused on the enzymes and genes that were involved in BPA degradation. Sasaki et al. (2005a) demonstrated that cytochrome P450 monooxygenase of Sphingomonas sp. strain AO1 was involved in BPA degradation for the first time. Enzymatic reaction of the P450 monooxygenase system in the presence of NADH was predicted to catalyze the attack on either a $\mathrm{C}$ atom of a methyl group or the quaternary 
carbon of BPA by $\mathrm{H}_{2} \mathrm{O}$. Hydroxylation of the methyl group converted BPA to the minor metabolite 2,2-bis(4hydroxyphenyl)-1-propanol, and hydroxylation of the quaternary carbon led to the formation of the major metabolite 1,2-bis(4-hydroxyphenyl)-2-propanol. In the simultaneous presence of NADPH and FAD, P450 monooxygenase was also reported to catalyze the ipso substitution in the BPA degradation by Sphingomonas sp. strain TTNP3. Various inhibitors of cytochrome P450 monooxygenase had identically inhibitory effects on the conversion of BPA (Kolvenbach et al. 2007). Beside P450 monooxygenase, an AMO from N. europaea and an extracellular laccase from Pseudomonas sp. strain were also involved in BPA degradation (Roh et al. 2009; Telke et al. 2009). However, the catalytic mechanism of the known enzymes still needs further investigation. For example, it is still necessary to detect the intermediates for the study of the reaction mechanism of the P450 monooxygenase system in BPA degradation. It is highly postulated that the relevant amounts and activities of the enzymes involved in the BPA degradation pathway are significantly varied in different bacterial strains. Thus, the new genes and enzymes involved in the BPA degradation also need to be explored.

Acknowledgement This work was financially supported by Innovation Projects of the Chinese Academy of Sciences grant KZCX2-EW206, the National Natural Science Foundation of China (NSFC) grant 31200041, the Doctoral Foundation of Shandong Province grant BS2011SW056, and the 100 Talents Program of the Chinese Academy of Sciences.

\section{Reference}

Alexander HC, Dill LW, Guiney PD, Dorn P (1988) Bisphenol A: acute aquatic toxicity. Environ Toxicol Chem 7:19-26

Bonefeld-Jørgensen EC, Long M, Hofmeister MV, Vinggaard AM (2007) Endocrine-disrupting potential of bisphenol A, biophenol A dimethacrylate, 4- $n$-nonyphenol, and 4- $n$-octylphenol in vitro: new data and a brief review. Environ Health Persp 115:69-76

Brugnera MF, Rajeshwar K, Cardoso JC, Zanoni MV (2010) Bisphenol A removal from wastewater using self-organized $\mathrm{TIO}(2)$ nanotubular array electrodes. Chemosphere 78:569-575

Cousins IT, Staples CA, Klecka GM, Mackay D (2002) A multimedia assessment of the environmental fate of bisphenol A. Hum Ecol Risk Assess 8:1107-1135

Deborde M, Rabouan S, Mazellier P, Duguet JP, Legube B (2008) Oxidation of bisphenol A by ozone in aqueous solution. Water Res 42:4299-4308

Dorn PB, Chou CS, Gentempo JJ (1987) Degradation of bisphenol A in natural waters. Chemosphere 16:1501-1507

European Commission (2003) European risk assessment report, bisphenol A, EUR20843EN

Fischer J, Kappelmeyer U, Kastner M, Schauer F, Heipieper HJ (2010) The degradation of bisphenol A by the newly isolated bacterium Cupriavidus basilensis JF1 can be enhanced by biostimulation with phenol. Int Biodeter Biodegr 64:324-330
Fu PQ, Kawamura K (2010) Ubiquity of bisphenol A in the atmosphere. Environ Pollut 158:3138-3143

Furhacker M, Scharf S, Weber H (2000) Bisphenol A: emissions from point sources. Chemosphere 41:751-756

Huang YQ, Wong CKC, Zheng JS, Bouwman H, Barra R, Wahlström B, Neretin L, Wong MH (2012) Bisphenol A (BPA) in China: a review of sources, environmental levels, and potential human health impacts. Environ Int 42:91-99

Ike M, Chen MY, Jin CS, Fujita M (2002) Acute toxicity, mutagenicity, and estrogenicity of biodegradation products of bisphenol-A. Environ Toxicol 17:457-461

Ike M, Jin CS, Fujita M (1995) Isolation and characterization of a novel bisphenol A-degrading bacterium Pseudomonas paucimobilis strain FJ-4. Jpn J Water Trt Biol 31:203-212

Ike M, Jin CS, Fujita M (2000) Biodegradation of bisphenol A in the aquatic environment. Water Sci Technol 42:31-38

Kaneco S, Rahman MA, Suzuki T, Katsumata H, Ohta K (2004) Optimization of solar photocatalytic degradation conditions of bisphenol A in water using titanium dioxide. J Photoch Photobio A $163: 419-424$

Kang JH, Katayama Y, Kondo F (2006a) Biodegradation or metabolism of bisphenol A: from microorganisms to mammals. Toxicology 217:81-90

Kang JH, Kondo F (2002a) Bisphenol A degradation by bacteria isolated from river water. Arch Environ Contam Toxicol 43:265-269

Kang JH, Kondo F (2002b) Effects of bacterial counts and temperature on the biodegradation of bisphenol $\mathrm{A}$ in river water. Chemosphere 49:493-498

Kang JH, Kondo F (2005) BPA degradation in river water is different from that in seawater. Chemosphere 60:1288-1292

Kang JH, Kondo F, Katayama Y (2006b) Human exposure to bisphenol A. Toxicology 226:79-89

Kang JH, Ri N, Kondo F (2004) Streptomyces sp. strain isolated from river water has high bisphenol A degradability. Lett Appl Microbiol 39:178-180

Kim JY, Ryu K, Kim EJ, Choe WS, Cha GC, Yoo IK (2007) Degradation of bisphenol $\mathrm{A}$ and nonylphenol by nitrifying activated sludge. Process Biochem 42:1470-1474

Klecka GM, Gonsior SJ, West RJ, Goodwin PA, Markham DA (2001) Biodegradation of bisphenol A in aquatic environments: river dieaway. Environ Toxicol Chem 20:2725-2735

Kolvenbach B, Schlaich N, Raoui Z, Prell J, Zühlke S, Schäffer A, Guengerich FP, Corvini PFX (2007) Degradation pathway of bisphenol A: does ipso substitution apply to phenols containing a quaternary $\alpha$-carbon structure in the para position? Appl Environ Microbiol 73:4776-4784

Li JH, Zhou BX, Shao JH, Yan QF, Liu YQ, Cai WM (2007) Influence of the presence of heavy metals and surface-active compounds on the sorption of bisphenol A to sediment. Chemosphere 68:1298 1303

Li G, Zu L, Wong PK, Hui X, Lu Y, Xiong J, An T (2012) Biodegradation and detoxification of bisphenol A with one newly-isolated strain Bacillus sp. GZB: kinetics, mechanism and estrogenic transition. Bioresour Technol 114:224-230

Liu Y, Sun WL, Ni JR (2011) Biodegradation of bisphenol A, 17 beta-estradiol, and 17 alpha-ethynylestradiol in river water. Int J Environ Pollut 45:225-236

Lobos JH, Leib TK, Su TM (1992) Biodegradation of bisphenol A and other bisphenols by a gram-negative aerobic bacterium. Appl Environ Microbiol 58:1823-1831

Masuda M, Yamasaki Y, Ueno S, Inoue A (2007) Isolation of bisphenol A-tolerant/degrading Pseudomonas monteilii strain N502. Extremophiles 11:355-362

Matsumura Y, Hosokawa C, Sasaki-Mori M, Akahira A, Fukunaga K, Ikeuchi T, Oshiman K, Tsuchido T (2009) Isolation and 
characterization of novel bisphenol-A-degrading bacteria from soils. Biocontrol Sci 14:161-169

Matsushima A, Kakuta Y, Teramoto T, Koshiba T, Liu XH, Okada H, Tokunaga T, Kawabata S, Kimura M, Shimohigashi Y (2007) Structural evidence for endocrine disruptor bisphenol A binding to human nuclear receptor ERR gamma. J Biochem 142:517-524

Melcer H, Klecka G (2011) Treatment of wastewaters containing bisphenol A: state of the science review. Water Environ Res 83:650-666

Neamtu M, Frimmel FH (2006) Degradation of endocrine disrupting bisphenol A by $254 \mathrm{~nm}$ irradiation in different water matrices and effect on yeast cells. Water Res 40:3745-3750

Nomiyama K, Tanizaki T, Koga T, Arizono K, Shinohara R (2007) Oxidative degradation of BPA using $\mathrm{TiO} 2$ in water, and transition of estrogenic activity in the degradation pathways. Arch Environ Contam Toxicol 52:8-15

Oehlmann J, Oetken M, Schulte-Oehlmann U (2008) A critical evaluation of the environmental risk assessment for plasticizers in the freshwater environment in Europe, with special emphasis on bisphenol A and endocrine disruption. Environ Res 108:140-149

Ohko Y, Ando I, Niwa C, Tatsuma T, Yamamura T, Nakashima T, Kubota Y, Fujishima A (2001) Degradation of bisphenol A in water by $\mathrm{TiO}_{2}$ photocatalyst. Environ Sci Technol 35:2365-2368

Oshiman K, Tsutsumi Y, Nishida T, Matsumura Y (2007) Isolation and characterization of a novel bacterium, Sphingomonas bisphenolicum strain AO1, that degrades bisphenol A. Biodegradation 18:247-255

Owens CV Jr, Lambright C, Bobseine K, Ryan B, Earl Gray Jr L, Gullett BK, Wilson VS (2007) Identification of estrogenic compounds emitted from the combustion of computer printed circuit boards in electronic waste. Environ Sci Technol 41:8506-8511

Peltonen K, Pukkila J (1988) Determination of bisphenol A in air by high-performance liquid-chromatography with electrochemical detection. J Chromatogr A 439:375-380

Roh H, Subramanya N, Zhao F, Yu CP, Sandt J, Chu KH (2009) Biodegradation potential of wastewater micropollutants by ammonia-oxidizing bacteria. Chemosphere 77:1084-1089

Ronen Z, Abeliovich A (2000) Anaerobic-aerobic process for microbial degradation of tetrabromobisphenol A. Appl Environ Microbiol 66:2372-2377

Saiyood S, Vangnai AS, Thiravetyan P, Inthorn D (2010) Bisphenol A removal by the Dracaena plant and the role of plant-associating bacteria. J Hazard Mater 178:777-785

Sajiki J, Yonokubo J (2002) Degradation of bisphenol A (BPA) in the presence of reactive oxygen species and its acceleration by lipids and sodium chloride. Chemosphere 46:345-354

Sajiki J, Yonokubo J (2003) Leaching of bisphenol A (BPA) to seawater from polycarbonate plastic and its degradation by reactive oxygen species. Chemosphere 51:55-62

Sakai K, Yamanaka H, Moriyoshi K, Ohmoto T, Ohe T (2007) Biodegradation of bisphenol $\mathrm{A}$ and related compounds by Sphingomonas sp. strain BP-7 isolated from seawater. Biosci Biotechnol Biochem 71:51-57

Sanchez-Avila J, Bonet J, Velasco G, Lacorte S (2009) Determination and occurrence of phthalates, alkylphenols, bisphenol A, PBDEs, $\mathrm{PCBs}$ and PAHs in an industrial sewage grid discharging to a municipal wastewater treatment plant. Sci Total Environ 407:4157-4167

Sasaki M, Akahira A, Oshiman K, Tsuchido T, Matsumura Y (2005a) Purification of cytochrome P450 and ferredoxin, involved in bisphenol A degradation, from Sphingomonas sp. strain AO1. Appl Environ Microbiol 71:8024-8030

Sasaki M, Maki J, Oshiman K, Matsumura Y, Tsuchido T (2005b) Biodegradation of bisphenol A by cells and cell lysate from Sphingomonas sp. strain AO1. Biodegradation 16:449-459
Sneath PHA, Mair NS, Sharpe ME, Holt JG (1986) In Bergey's manual of systematic bacteriology, vol 2 (ed by) Williams \& Wilkins. Baltimore 2:1104-1207

Snyder SA, Villeneuve DL, Snyder EM, Giesy JP (2001) Identification and quantification of estrogen receptor agonists in wastewater effluents. Environ Sci Technol 35:3620-3625

Spivack J, Leib TK, Lobos JH (1994) Novel pathway for bacterial metabolism of bisphenol A. Rearrangements and stilbene cleavage in bisphenol A metabolism. J Biol Chem 269:7323-7329

Staples CA, Dorn PB, Klecka GM, O'Block ST, Harris LR (1998) A review of the environmental fate, effects, and exposures of bisphenol A. Chemosphere 36:2149-2173

Suzuki T, Nakagawa Y, Takano I, Yaguchi K, Yasuda K (2004) Environmental fate of bisphenol A and its biological metabolites in river water and their xeno-estrogenic activity. Environ Sci Technol 38:2389-2396

Takahashi S, Chi XJ, Yamaguchi Y, Suzuki H, Sugaya S, Kita K, Hiroshima K, Yamamori H, Ichinose M, Suzuki N (2001) Mutagenicity of bisphenol A and its suppression by interferon-alpha in human RSa cells. Mutat Res 490:199-207

Tanghe T, Dhooge W, Verstraete W (1999) Isolation of bacterial strain able to degrade branched nonylphenol. Appl Environ Microbiol 65:746-751

Telke A, Kalyani DC, Jadhav UU, Parshetti GK, Govindwar SP (2009) Purification and characterization of an extracellular laccase from a Pseudomonas sp. LBC1 and its application for the removal of bisphenol A. J Mol Catal B: Enzym 61:252-260

Toyama T, Sato Y, Inoue D, Sei K, Chang YC, Kikuchi S, Ike M (2009) Biodegradation of bisphenol A and bisphenol $\mathrm{F}$ in the rhizosphere sediment of Phragmites australis. J Biosci Bioeng 108:147-150

Ulutao OK, Yildiz N, Durmaz E, Ahbab MA, Barlas N, Çok Ã (2011) An in vivo assessment of the genotoxic potential of bisphenol A and 4-tert-octylphenol in rats. Arch Toxicol 85:995-1001

Yamamoto T, Yasuhara A, Shiraishi H, Nakasugi O (2001) Bisphenol A in hazardous waste landfill leachates. Chemosphere 42:415-418

Yamanaka H, Moriyoshi K, Ohmoto T, Ohe T, Sakai K (2007) Degradation of bisphenol A by Bacillus pumilus isolated from kimchi, a traditionally fermented food. Appl Biochem Biotech 136:39-51

Yamanaka H, Moriyoshi K, Ohmoto T, Ohe T, Sakai K (2008) Efficient microbial degradation of bisphenol $\mathrm{A}$ in the presence of activated carbon. J Biosci Biogen 105:157-160

Ying GG, Kookana RS, Kumar A (2008) Fate of estrogens and xenoestrogens in four sewage treatment plants with different technologies. Environ Toxicol Chem 27:87-94

Zhang WW, Chen LX, Liu DY (2012a) Characterization of a marineisolated mercury resistant Pseudomonas putida strain SP1 and its potential application for marine mercury reduction. Appl Microbiol Biotechnol 93:1305-1314

Zhang WW, Niu ZL, Yin K, Liu F, Chen LX (2013) Degradation of furazolidone by bacteria Acinetobacter calcoaceticus T32, Pseudomonas putida SP1 and Proteus mirabilis V7. Int Biodeter Biodegr 77:45-50

Zhang WW, Wen YY, Niu ZL, Xu DX, Yin K, Chen LX (2012b) Isolation and characterization of sulfonamide-degrading bacteria Enterobacter sp. HS21 and Acinetobacter sp. HS51. World J Microbiol Biotechnol 28:447-452

Zhang WW, Xu DX, Niu ZL, Yin K, Liu P, Chen LX (2012c) Isolation and characterization of Pseudomonas sp. DX7 capable of degrading sulfadoxine. Biodegradation 23:431-439

Zhang C, Zeng G, Yuan L, Yu J, Li J, Huang G, Xi B, Liu H (2007) Aerobic degradation of bisphenol A by Achromobacter xylosoxidans strain B-16 isolated from compost leachate of municipal solid waste. Chemosphere 68:181-190 